\title{
La censura y Memorias de Paulina
}

\author{
Adriana Sandoval \\ Instituto de Investigaciones Filológicas \\ Universidad Nacional Autónoma de México
}

Tal vez uno de los casos más famosos de censura en México ha sido el del poeta José Juan Tablada. Alguien cercano a la presidencia llamó la atención de doña Carmelita de Díaz hacia la publicación del poema "Misa negra" en el periódico El País. Tablada, a tono con los decadentes finiseculares franceses, utilizó ahí un lenguaje erótico y baudeleriano contrario a la ética ortodoxa de la Iglesia católica, y por ende, a la moral porfiriana. Como consecuencia, el poeta publicó su renuncia al periódico donde trabajaba, el 15 de enero de $1893 .{ }^{1}$ La censura tuvo una afortunada consecuencia, pues llevó a la fundación de la Revista Moderna. En este caso, hasta donde sé, no se aplicó la ley; se trató más bien de una ofensa a la moral pública, personificada en la esposa del presidente de la República.

Otro ejemplo célebre, éste de índole político-militar, fue la aparición de Tomóchic. La publicación de la novela por entregas casi le costó la vida a su autor, el entonces subteniente Heriberto Frías. ${ }^{2}$ En este caso se trataba de una doble infracción: la traición a la patria, entendida ésta como la institución militar, y la violación de un secreto profe-

\footnotetext{
${ }^{1}$ Véase mi prólogo al volumen V: Crítica literaria de las Obras de José Juan Tablada, donde se incluye la carta de renuncia (Sandoval 1994).

${ }^{2}$ Para lo relativo a Frías, véase Los doblados de Tomóchic de Antonio Saborit y mi estudio introductorio a dos de las novelas de la trilogía autobiográfica de Frías, El triunfo de Sancho Panza (Mazatlán), continuación de Tomóchic y Miserias de México (Sandoval 2004). Georgina García-Gutiérrez tiene en preparación una edición de la misma novela.
} 
sional. Tomóchic se publicó de manera anónima, en el periódico de Clausell. Cuando las entregas llamaron la atención de los mandos militares, se intentó ubicar al autor: si era Frías, podía juzgársele por traición al revelar información militar. Por ello, Clausell se presentó como autor del texto y logró salvar a su amigo del pelotón de fusilamiento. Frías, sin embargo, figuró posteriormente como autor de la novela. Aquí la censura sí llegó a los tribunales.

Sin que las consecuencias llegaran a estos extremos de vida o muerte, las Memorias de Paulina también aparecieron de manera anónima; el librito no incluía la información reglamentaria sobre el editor ni la ubicación de la imprenta. Se detectó como editor a Jorge Ainslie, quien compareció en el juicio como el responsable y, en esa misma calidad, sufrió el castigo consiguiente. En el curso del escándalo salió una segunda impresión del escrito, igualmente sin pie de imprenta.

\section{José Negrete}

Aunque su nombre completo era José María Martínez Negrete, el de escritor que usó fue la forma abreviada "José Negrete", con la que se le conoce. Negrete, nos informa "G.B." en su "Presentación" a Memorias de Paulina, vivió tan sólo 28 años (Bruselas 1855-Tepic 1883). Era hijo de un diplomático mexicano enviado a Bélgica, donde nació. Ya avecindado en México (a partir de los once años), asistió al Colegio de San Ildefonso y luego estudió Leyes en la Escuela Nacional de Jurisprudencia. Fue diputado, novelista, traductor y periodista. Participó en $L a$ Revista Universal como redactor. En política fue defensor de Sebastián Lerdo de Tejada y combatió a los partidarios del Plan de Tuxtepec. Hasta aquí la información de "G.B."

Negrete murió en Tepic, aunque algunas noticias iniciales dieron como lugar de su deceso Guadalajara. Ese año de 1883 una epidemia asoló varios estados. El frágil cuerpo de nuestro autor terminó su lucha con la enfermedad el 24 de agosto (Ángela Peralta murió el 31 del mismo mes en Mazatlán, también de "fiebre perniciosa").

Entre sus producciones, los estudiosos del XIX incluyen Memorias de Paulina (1874), Historias color de fuego (1875), La niña mártir: páginas de una causa célebre: novela (1878), La mujer verdugo (1878: segunda parte del texto precedente), Memorias de merolico (1880), El verdadero 
Porfirio Díaz (1911), La hecatombe de Veracruz $(1880,1910)^{3}$ y la traducción de La hija adoptiva de Alejandro Dumas (1878). Hasta donde sé, sólo se han reeditado las Memorias de Paulina, junto con las Memorias de merolico, en la edición de Fernando Tola (colección La Matraca).

Negrete es uno de los escritores menores del siglo antepasado, apenas mencionado en las historias de la literatura mexicana, o incluso ignorado: Warner no lo incluye y tampoco Carballo; Jiménez Rueda no lo menciona, ni González Peña; Altamirano lo soslaya, al igual que López Portillo, Federico Gamboa y Rafael Delgado; Oseguera tampoco habla de él. Me interesa desenterrarlo, no tanto por motivos literarios - escasos - sino por documentar un asunto de censura.

\section{EL LIBRITO}

Las Memorias de Paulina son los supuestos recuerdos narrados en primera persona, de una bailarina francesa, de la vida galante, avecindada en la ciudad de México.

Especulo que Negrete aspiraba tal vez a escribir un texto en la corriente picaresca, similar a Moll Flanders (1772) de Daniel Defoe. Esta última novela, por cierto, también fue objeto de censura, si bien no en el momento de su aparición, cuando gozó de una venta exitosa inmediata - con tres ediciones en el primer año, y luego de un éxito moderado, pero sostenido: una edición anual durante los siguientes sesenta (Karolides: 367). Sin embargo, ya para la época victoriana sólo era posible leerla en algunas ediciones de las obras completas de Defoe o en impresiones anteriores. A principios del siglo Xx, se impidió el ingreso de Moll Flanders a los Estados Unidos por considerarlo un libro "obsceno".

Vale la pena citar el subtítulo completo de Defoe: "The Fortunes and Misfortunes of the famous Moll Flanders, orc, who was born in Newgate, and during a life of continued variety, for threescore years, besides her childhood, was twelve years a Whore, five times a Wife (whereof once to her own brother), twelve years a Thief, eight years a transported Felon in Virginia, at last grew rich, lived honest, and died a Penitent.

\footnotetext{
${ }^{3}$ Esta obra aparece en el catálogo de la Biblioteca Nacional, pero no en el Fichero de Ángel Muñoz Fernández.
} 
Written from her own Memorandums" (1969). ${ }^{4}$ El larguísimo subtítulo, de claro corte mercadotécnico — una probadita del contenido para ganar la atención y curiosidad del posible lector- pretende, muy al final, muy en el fondo, cumplir un propósito moral, puesto que Moll termina su vida de manera honesta y muere como una penitente. La última parte de su vida, ya dentro de la ley y la moral, es sin embargo, la más corta y, en cierto sentido, aburrida; de modo que, pese a las supuestas intenciones moralistas de Defoe, predomina lo inmoral e ilegal, casi siempre narrado con sentido del humor. ${ }^{5}$

La narración temporal de la vida de Paulina no es tan larga ni detallada — aunque se remonta a su nacimiento e infancia. La Paulina de Negrete sólo registra algunos años de su vida, y en realidad se trata más bien de comentarios sobre la vida en México vista desde su personal punto de vista. El final permanece abierto, con la bailarina a punto de embarcarse en Veracruz rumbo a Europa. Por ello, no hay oportunidad de que se case, ni se arrepienta, ni nada por el estilo. No recibe ningún castigo por su conducta inmoral. ${ }^{6}$ Pero tampoco hay incitación al vicio ni a la inmoralidad ni al delito — lo cual podría constituir un delito.

\section{AnTECEDENTES}

A sus escasos veinte años, Negrete era un periodista provocador. En los artículos publicados en la Revista Universal antes del escándalo de las

4 "Las fortunas y los infortunios de la famosa Moll Flanders, etc., nacida en Newgate, quien, durante una vida que abarcó tres décadas, sin incluir su infancia, fue prostituta durante doce años, esposa cinco veces (una de esas ocasiones de su propio hermano), doce años fue ladrona, ocho una convicta, enviada a Virginia; finalmente se hizo rica, llevó una vida honesta y murió como penitente. Basada en sus propias memorias" (la traducción es mía).

${ }^{5}$ Naná ya estaba cerca: 1880. Los Goncourt habían publicado Germinie Lacerteux en 1865 .

${ }^{6}$ Recordemos que en las novelas del siglo XIX a las adúlteras se les castiga de manera ejemplar: Emma Bovary; antes de morir, Effie Briest queda condenada al ostracismo social apartada de su hija; Anna Karenina termina despedazada bajo las ruedas de un tren; Ana Ozores en La Regenta no muere físicamente, pero queda condenada a vivir deshonrada (una muerte moral); Luisa en El primo Basilio muere de una enfermedad después de que el marido descubre su pecado. Vale mencionar también el juicio que sufrió Flaubert, en parte precisamente por no haber condenado explícitamente en el texto a la adúltera Emma. 
Memorias, ataca y critica sin misericordia a la prensa, a las presentaciones de la ópera bufa en México, a las actrices y cantantes, al público que asistía, a los pollos encantados con las bailarinas, a las señoritas que saben los nombres de las cortesanas de moda...

En una sección denominada "Epístolas a mi abuela" mezclaba sus críticas teatrales con comentarios de otro tipo. Inició también una serie dedicada a los usureros más conocidos del país, sin nombrar a ninguno, pero describiéndolos de manera que el público seguramente sabía a quiénes se refería. ${ }^{8}$ En dos de estos artículos se refiere a ellos con nombres tomados de Balzac: Nucingen y Gobseck. El primer personaje aparece en Le père Goriot y es un banquero de origen alemán, deseoso de formar parte de la añeja aristocracia francesa. Gobseck aparece en varias de las novelas, y es el epítome del usurero balzaciano, junto con Grandet.

El joven escritor dedicó otra serie de artículos al estado de la prensa mexicana, pasando revista a los periódicos publicados en esa época, bajo una lente nada favorecedora. No asombra, pues, que haya habido animadversión hacia él en los medios impresos.

\section{La censura en el MéXico decimonónico}

María del Carmen Reyna documenta 162 juicios en México, entre 1813 y 1882, clasificados como Jurados de Imprenta. De éstos, sólo tres alcanzaron una pena de 12 años, mientras que otros solamente recibieron 15 días de castigo. En 1871 fue cuando se registraron más casos (15); siguen en cantidad los años 1868, 1869 y 1827. Hay que aclarar, sin embargo, que estos casos son generales y no siempre se refieren específicamente a cuestiones morales o sexuales. De hecho, éstos constituyen una minoría (alrededor de un 5\%) (Reyna 1976). ${ }^{\text {? }}$

\footnotetext{
${ }^{7}$ El título no deja de ser chusco. Alude, claro está, al refrán popular que involucra a la abuela: a nadie le interesa lo que escribe, que se lo cuente a su abuela, es la idea que está detrás.

${ }^{8}$ Varios artículos o folletos que en su momento levantaron ámpulas, nos resultan incomprensibles porque no reconocemos de inmediato, como seguramente sí lo hacía el público del momento - y sobre todo los aludidos— a los que eran objeto de burla o escarnio.

${ }^{9}$ Véase también Piccato 2004.
} 
Después de las numerosas vicisitudes políticas del siglo XIX, con la restauración de la República Juárez decreta la libertad de imprenta — una vez más - en febrero de 1861. En el rubro que nos concierne se establece que:

Se ataca a la moral defendiendo o aconsejando los vicios o delitos. [...]

Las faltas a la vida privada se castigarán con prisión que no baje de 15 días ni exceda de seis meses.

Las faltas a la moral se castigarán con prisión de un mes a un año (Reyna: 47).

En febrero de 1868 se decretó la Ley orgánica de la libertad de imprenta, muy similar a la previa de 1861. En 1870 se indicó a los editores la obligación del cumplimiento del artículo 34 —infringido por Memorias de Paulina - que establece que los impresos deben llevar la información del editor y la imprenta.

Hoy en día rige la Ley de imprenta emitida por Venustiano Carranza el 12 de abril de 1917.

\section{LA NOVELA IMPUGNADA}

La aparición de la novela se inicia el 12 de septiembre de 1874, cuando la Revista Universal — de la que formaba parte Negrete como redactor- publica en la sección "Recreaciones sabatinas", con el subtítulo "Cartas al sentido común", algunas ideas sobre diversas cuestiones, firmadas por "José Negrete". Estas líneas formarán luego parte del folleto publicado como Memorias de Paulina, en particular, de los capítulos X ("La virtud") y XVII (“Amor platónico").

El 18 de septiembre de 1874 la misma revista publicó en la sección "Gacetilla"10 la noticia de que acababan de recibir desde Veracruz un paquete con un cuaderno acompañado de una carta, que transcriben:

\footnotetext{
${ }^{10}$ Vale mencionar que en las secciones de "gaceta" o "gacetilla" de muchos periódicos se practicaban plagios abiertos de manera usual. Muchas publicaciones refriteaban lo aparecido en otras, sin mencionar la fuente de la noticia.
} 
Amigos míos:

Antes de embarcarme quiero mandarles el diario de mis impresiones y aventuras en México. Puesto que ustedes no han vacilado en honrar mis revistas de modas publicándolas en su ilustrado periódico, espero que dispensarán igual favor al folleto que les remito.

Nosotras las mujeres tenemos un modo especial de juzgar a los hombres y a las cosas; por eso siempre me ha parecido un error el no consultarlas cuando se trata de fotografiar una época y una sociedad.

La suerte me ha colocado en esa categoría de mujeres que Dumas hijo llama "des pêches a quinze sous", podrá ser una fatalidad, como decía la bella Elena, pero nunca un crimen.

El autor de Los tres mosqueteros ha escrito una obra que se llama Los grandes hombres en bata. No es una fatuidad pero creo poder retratar a muchas notabilidades mexicanas en un traje todavía más sencillo. Pero basta de charla, ustedes tienen la obra y a ustedes les pertenece juzgarla.

Paulina

Debajo de la supuesta carta, la redacción anotó:

Somos demasiado galantes y creemos [sic] de un interés demasiado palpitante para no obsequiar los deseos de nuestra bella colaboradora.

No hemos tenido tiempo de leer la obra, pero por los títulos de los capítulos, está llamada a causar gran sensación.

Mañana publicaremos los títulos de los capítulos y extractaremos algunos en la semana entrante.

El 4 de octubre, en la sección "Ecos de todas partes", la Revista avisa que hace unos días publicaron un fragmento llamado "Memorias de Paulina" "con el que sólo pretendimos hacer reír a nuestros lectores”, pero como el día anterior (es decir, el 3 de octubre) apareció un folleto con el mismo título, la redacción se deslinda de esa publicación. A partir de entonces empieza el escándalo que duró hasta el fin del año de 1874.

El mencionado folleto apareció bajo el sello de la Imprenta Políglota, sita en la calle de Santa Clara, "esquina al callejón”, aunque no se menciona responsable legal alguno. Para cuando se juzgó el caso, como no se había identificado al autor, se procedió legalmente en contra de 
quien se había identificado como editor: Jorge Ainslie — como ya mencionamos antes-. ${ }^{11}$

En Memorias de Paulina, la protagonista cuenta sus impresiones en un tono desenfadado y ajeno a cualquier reflexión moral, o mejor dicho, con flagrantes transgresiones a la moral de la época. La narradora hace generalizaciones sobre las mujeres y pone en primer lugar su placer, su confort, su vanidad, frente a instituciones consideradas sagradas como el matrimonio, la familia, o consideraciones morales como el pudor, la vergüenza, etc.; se embarca en numerosas relaciones con hombres, a los que no tiene gran aprecio ni consideración.

Antes de continuar, hay que indicar que el texto difícilmente calificaría como novela, en la medida en que no existe una trama con principio, medio y fin, con algún desarrollo narrativo; tampoco hay desarrollo de personajes; prácticamente no hay anécdotas. Se trata, más bien, de una serie de anotaciones sin mayor ilación, como una especie de diario, de impresiones y opiniones de la narradora, que la llevan a hacer comentarios sobre algunos aspectos de la vida en México, sobre las mujeres, los hombres, la prensa, las jóvenes mexicanas, el matrimonio, etc. No hay mayor profundización ni en el personaje de la voz narradora ni en aquellos con los que se encuentra; salvo uno, los demás no merecen ni siquiera un nombre propio. En la prensa no se refieren a ella como novela, sino como folleto - posiblemente debido a su corta extensión- acompañado del adjetivo "infame", o bien como "libelo".

El texto empieza con Paulina (no su nombre verdadero) en París, con algunos breves comentarios sobre dónde y cuándo nació (1850): fue hija de una madre soltera abandonada por su seductor. A muy temprana edad (once años) fue contratada para bailar por el director de un ballet de teatro de tercer orden, quien además fue el encargado de iniciarla en las actividades sexuales (ella dice: "el bautismo de fuego": 13). Frente a la determinación de su destino, Paulina opta por sumergirse de lleno no sólo en la prostitución corporal, sino en la de su imaginación: "combatí el veneno de la lujuria con el frío indiferentismo de mi carácter” (13), que será evidente a lo largo del texto.

En Francia un caballero mexicano la invita a venir a México, donde pasa algún tiempo. El texto termina aquí, cuando Paulina se dispone a

\footnotetext{
${ }^{11}$ En ninguno de los artículos periodísticos consultados se informa cómo se llegó a la conclusión de que Ainslie era el editor responsable.
} 
volver a Francia: se lo han pedido, el padre de Perico, ${ }^{12}$ uno de sus amantes, y un banquero, cuya esposa lo ha amenazado en caso de seguir su relación con la francesa. Ambos han cubierto los costos del billete y del viaje. Un epílogo quiere suscitar suspenso: se pregunta una voz, que parece corresponder más a un narrador externo que a la voz femenina que ha escrito el texto, si Paulina llegó a embarcarse o no.

Algunos de los títulos de los capítulos constituyen una provocación a la moral mexicana decimonónica: "Aventura nocturna" (II), "Primeras armas" (III), "Una orgía” (IV), “Adulterio” (V).

Entre las críticas de la cortesana están las que hace a la prensa mexicana ("La prensa en México" VI). La narradora se declara interesada en la lectura: "La prensa representa en México el último escalón de la barbarie" (28); es su primer comentario con respecto al periodismo mexicano. Critica ácidamente a los reporteros, afirmando que "no se atreven a ser libres teniendo miedo de comprometer o de errar el cálculo de sus intereses" (29). Algunos son cada vez más cínicos, otros más son ambiciosos pero todos son confusos. Todos siguen sus intereses en busca de prebendas o dádivas, no se comprometen, "y esperan recompensas o transacciones, inspiradas por el temor” (29).

A continuación menciona específicamente a cuatro periódicos: $E l \mathrm{Fe}$ deralista, ${ }^{13}$ El Monitor Republicano, El Ahuizote ${ }^{14}$ y La Revista Universal ${ }^{15}$ (29). El primero es una especie de comparsa, de clown; el segundo "se contenta con estar redactado a la altura de sus lectores, la hez de la canalla" (29); el tercero "es una triste parodia del talento francés" (30); y el cuarto "se enorgullece de haberse convertido de poco tiempo a esta parte en libelo infamatorio" (30) — que no deja de ser un comentario curioso, puesto que en esa misma publicación colaboraba el propio Negrete,

12 No puede uno sino evocar la conmovedora escena en La Traviata de Verdi (1853), donde el padre de Alfredo le pide a Violeta que abandone a su hijo, a lo que ella accede, pensando en su bien. A diferencia de Paulina, la "traviata", una heroína romántica, no acepta dinero a cambio de poner fin a la relación: es una "prostituta de buen corazón".

13 Tanto este periódico, dirigido por el francés Alfredo Bablot, como El Constitucionalista, apoyaron a Juárez en las elecciones de 1871 (Diccionario Enciclopédico de México).

${ }^{14}$ Fue fundado en 1874 (ibidem).

${ }^{15}$ Este periódico, fundado en 1867, se contaba entre los conservadores de la época (ibidem). 
y fue ahí mismo donde se dieron a conocer los avances de las Memorias - Este último comentario podría ser, pues, una especie de autocrítica no exenta de ironía. Y concluye la narradora el capítulo: "Depravación y cinismo con pretensiones de honradez y de equidad, tal es el balance de la prensa, que ha sido dividida por un poeta que padece la epilepsia del valor, en dos grandes familias: periódicos vendidos y periódicos que están de venta" (30). De nuevo hay una alusión al propio Negrete, con quien podemos identificar al "poeta" enfermo de la "epilepsia del valor", que había estado haciendo un recuento sumamente crítico de la prensa mexicana en las columnas de la Revista. Como se ve en estas afirmaciones, hay simplemente la intención de provocar, de irritar, incluso tal vez de ofender, sin pruebas ni argumentos. No resulta asombroso que los aludidos - la prensa - hayan reaccionado agriamente ante estos comentarios.

Nos detendremos en dos de los capítulos, el $\mathrm{V}$ y el $\mathrm{X}$, que fueron esgrimidos por el denunciante en contra del autor durante el juicio. El V se llama "Adulterio". En él declara Paulina no entender la imposición de la indisolubilidad del matrimonio: las parejas que no se soportan, por las razones que sean, debían de optar por la separación. Considera la narradora, de entrada, que el matrimonio es una suerte de cárcel de la que no se puede escapar. La idea de la felicidad dentro del matrimonio es una quimera: las pasiones no son eternas. Hace luego una comparación entre las asociaciones entre un tutor y su pupilo, o dos socios que pretendieran establecer una relación para siempre; sería absurdo, dice. Para la mujer, el matrimonio es una esclavitud. Si el matrimonio sirve para la satisfacción de la libido, del "imperioso deseo del amor", dice ella, no es necesario amenazar la relación con la indisolubilidad. Por todo ello, declara, defiende la libertad, es decir, la soltería. Muchas mujeres, continúa, tal vez sean capaces de resistir el adulterio propiamente dicho, pero se entregan al "adulterio espiritual" (27). El resto del capítulo habla ya de otras cuestiones.

Como se ve, las opiniones de la narradora van claramente en contra de los valores establecidos en torno a la familia, a la fidelidad, al matrimonio, dentro de una sociedad en la que tanto conservadores como liberales defendían a la familia como una de las instituciones sociales más importantes. Negrete se atreve incluso a hablar de las fantasías sexuales no declaradas de las mujeres, solteras o casadas.

En el capítulo denominado "La virtud" (X) la narradora continúa con su tono desenfadado. Comenta que algunas mujeres se han referido a ella como "una mala mujer" (37). Retoma la idea planteada en el capítulo 
"Adulterio" en torno a la diferencia entre la castidad física y la mental de las mujeres. Todas, reafirma, son culpables de fantasías sexuales. A continuación, usando a Murger ${ }^{16}$ como apoyo, afirma que el "amor platónico es tan insípido como un vaso de agua teñida con unas gotas de vino”. La inocencia de la mujer, comenta, es un mito inventado por el hombre. Las fantasías femeninas se revelan en signos como "la frente velada, las manos húmedas y temblorosas" (38). En este capítulo aparece una autocita del autor, aunque aquí en labios de la narradora Paulina: "Como decía muy bien en uno de sus artículos el joven escritor José Negrete, es una injusticia que el contacto de las dos epidermis sea eliminado de las conversaciones para evitar el rubor que sienten las niñas al oír pronunciar su nombre" (39). No cuesta trabajo, de nuevo, imaginar la indignación de muchas personas al leer que alguien osaba sugerir que es imposible imaginar a una doncella totalmente pura en la imaginación.

Un detalle curioso: la narradora resulta ser una ambientalista consciente avant la lettre, al manifestarse contra los materiales potencialmente tóxicos para el uso humano. Menciona los juguetes con que se divierten los niños mexicanos: muñecas con caras blanqueadas con "tinte de España" y trompetas con "cromato de plomo" — sustancias potencialmente tóxicas- Las flores artificiales que sirven para adornar los peinados de las jóvenes, prosigue, contienen una sal arsénico; los encajes se lavan con carbonato de plomo (34).

\section{LOS COMENTARIOS EN LA PRENSA ${ }^{17}$}

Desde que empezó a circular, las Memorias de Paulina fueron objeto de críticas y comentarios en la prensa periódica, que se sucedieron en particular durante el mes de octubre.

Uno de los primeros periódicos en reaccionar contra la novela fue El Monitor Republicano, ${ }^{18}$ aludido por el autor de las Memorias. En la

\footnotetext{
16 Louis-Henri Murger (1822-1861) es el autor de Scènes de la vie de bohème (1847-49) utilizada por Puccini para su célebre ópera La bohème.

17 Agradezco a Lourdes Juárez, de la Universidad de Guerrero, su colaboración para la investigación hemerográfica, como parte de su estancia en el "Verano de la investigación 2005", auspiciada por la Academia de las Ciencias.

${ }^{18}$ Vicente García Torres (Pachuca 1811-D.F. 1893) era el dueño y fundador del periódico (1844), el segundo en importancia en el siglo antepasado, después de El Siglo XIX.
} 
sección "Gacetilla" (4 de octubre de 1874) se dice que se "tienen noticias" de que en el libro "se insulta indignamente a la prensa, al Congreso, al gobierno, a caballeros muy conocidos de esta sociedad, y aun a las señoras mexicanas". Se afirma que los insultos al Monitor se deben sin duda a "la independencia con que este diario se redacta". A fin de concitar la solidaridad de los lectores, continúa con la idea de que también se les insulta a ellos, por preferir la verdad del periódico. El autor, se sostiene, ha pretendido hacerse fama de mala manera, "escupiendo el rostro de la sociedad". El artículo termina agradeciendo los insultos y confiando en que el libro será despreciado.

En la "Sección editorial" del mismo Monitor, bajo la firma de "Juvenal" ${ }^{19}$ el 7 de octubre, se abunda con respecto a la historia de Memorias de Paulina, siempre en tono reprobatorio. Comienza enumerando los sitios en donde se ha vendido el "prospecto": en las esquinas de las calles, plazas, tabernas, teatros, "casas de baja estofa". La supuesta autora es una prostituta francesa, a la que califica como "una de esas moscas sociales que se alimentan de pústulas". ${ }^{20} \mathrm{El}$ texto no es otra cosa que "la crónica desvergonzada de una pobre ramera, en la cual se complicaban multitud de personas conocidas en la sociedad mexicana". Allí, continúa, "se atacaba, con la osadía del insensato y el rebajamiento del miserable, el honor de los hombres, el buen nombre de las familias, el decoro de las damas, la prensa, los poderes de la nación, cuanto tiene de más santo el hogar, cuanto tiene de más alto la sociedad civilizada!"

Otros comentarios a la novela aparecieron en la sección "Canto llano" de La Orquesta (7 de octubre de 1874): allí se refiere la publicación de un "libelo infamatorio", donde "materialmente se pone de asco a toda la sociedad mexicana, sin respetar ni lo más sagrado". Por su parte, la sección "Gacetilla” de El Siglo XIX (8 de octubre de 1874) califica al texto de igual manera ("libelo infamatorio") e indica que cuesta dos pesos. Se queja del anonimato del autor, y dice que los redactores de la Revista Universal: Peniche, Gostkowski, ${ }^{21}$ Santa María

\footnotetext{
19 Seudónimo de Enrique Chávarri.

${ }^{20}$ Estos términos parecen salidos directamente de una novela de Zola. Nana aparece en folletín cinco años después (1879), pero Thérèse Raquin, el primer éxito y escándalo de Zola, había aparecido en 1868.

${ }^{21}$ El barón de Gostkowski (Polonia 1856-Francia 1901), fue periodista, empresario teatral, dramaturgo, escritor. Entre 1871 y 1873 dirigió El Domingo (Diccionario Enciclopédico de México).
} 
y Negrete (!) han negado participación alguna en el libelo. El referido Negrete resultó ser, en realidad, el autor del mencionado texto.

El 9 de octubre, en la misma sección "Gacetilla”, se cita al periódico de corte legal, El Foro, con respecto al artículo 17 de la ley de imprenta, donde se establece que la ley castigará los delitos que hayan sido denunciados "por la acción popular" o por el ministerio fiscal. En el caso de las Memorias, nos enteraremos más adelante, se trató de un denunciante particular que actuó en representación de la "acción popular".

El 10 de octubre de 1874, en "Canto llano" de La Orquesta, ${ }^{22}$ se aplaude la denuncia del libro, calificándolo de obra "infame". Si se castiga al autor, prosigue, tal vez éste aprenda "a respetar la sociedad en que vive"; se critica luego el anonimato del escrito: "para los libelos, desprecio; para los libelistas, ignominia". ${ }^{23} \mathrm{Y}$ termina diciendo: "La sociedad de México podrá tener muchos defectos, pero no le falta saliva que arrojar a la cara de los maldicientes y calumniadores".

Quienes se han ocupado del tema de la censura han mencionado uno de sus efectos paradójicos, a saber, la promoción de la curiosidad del público, acicateada por el atractivo de la transgresión, que ocasiona, en no pocas ocasiones, que el libro prohibido se lea más que si no hubiera sido censurado. Esto sucedió con Memorias de Paulina, y así se hizo notar en la "Gacetilla" del 15 de octubre de 1874:

la importancia que se le ha querido dar a un escrito despreciable en sí mismo, y que según la opinión de personas sensatas que lo han leído, no merecía la pena de los honores del juicio, es lo que ha promovido su lectura, provocando la curiosidad de toda clase de personas. Sin embargo, siempre será honroso para una sociedad culta y moralizada, que producciones de esa especie exciten su indignación y sufran el correctivo que la ley les impone.

El Pájaro Verde, ${ }^{24}$ por su parte, en su sección "Judicial” del 16 de octubre del mismo año, publica la denuncia presentada por Eulalio

22 Este periódico, que había satirizado a Juárez, fue sometido a juicio una vez restaurada la República. "El periódico fue suspendido y multado varias veces y sus redactores visitaron con frecuencia la prisión” (Diccionario Enciclopédico de México).

23 Piccato nos recuerda que los pasquines estaban prohibidos desde 1808 como escritos anónimos (155).

${ }^{24}$ A principios de 1861, ya derrotados los conservadores, aparecieron (o reaparecieron) varios periódicos en la ciudad de México, entre los cuales se encontraba $E l$ 
María Ortega, ${ }^{25}$ con fecha 10 de octubre de 1874 , donde se menciona, entre otras cosas, que Memorias de Paulina:

Además de su inmoralidad general, que es el carácter principal que en él domina, han sido cruelmente difamadas en el mismo, varias personas, retratándolas de manera que, aunque sin expresar sus nombres, todos los que las tratan con alguna intimidad, no pueden dejar de reconocerlas y de señalarlas fácilmente con el dedo.

Sin embargo, comenta el mismo texto, ninguna de estas personas ha presentado una denuncia. El autor del artículo piensa que con respecto a un libro como Memorias de Paulina, "cuya inmoralidad y cinismo no tienen ejemplo en los anales de nuestra imprenta, es un deber de todo el que estima la libertad de ésta y desea que esa institución no se desacredite, denunciar aquella publicación, cualquiera que sea el resultado del juicio que se siga”. Este articulista considera que el autor del libro ha abusado de la libertad de prensa, "la más importante de las libertades públicas". Coincide en la crítica centrada en los capítulos V (“Adulterio") y X ("La virtud"). En el primero se ataca la indisolubilidad del matrimonio, y en el segundo se hace un paralelo "entre la mujer honrada y la cortesana”. El articulista se refiere también a la ausencia del nombre de autor que viola el artículo 34 de la Ley de imprenta: "y sin expresar el nombre del propietario tipográfico en que se hizo la impresión, violación prevista por el artículo 42 de la misma ley”. El denunciante pide la máxima pena para los infractores. Termina con la presentación de una segunda edición de Memorias de Paulina, infringiendo de nuevo la Ley de imprenta del 4 de febrero de 1868, pues, como la primera, carece de autor y pie de imprenta. Cabe mencionar que este mismo periódico publicó el 24 de octubre el mismo "jurado de sentencia" mencionado en el siguiente párrafo tomado de El Siglo XIX (19 de octubre).

Ya para el 19 de octubre, en El Siglo XIX, la información sobre el libelo está ampliada. El señor licenciado Eulalio M. Ortega ha denun-

Pájaro Verde: una publicación sumamente conservadora, de hecho imperialista, cuyo título, se decía, era un anagrama de "arde, plebe, arde" (Diccionario Enciclopédico de México).

${ }^{25}$ En este periódico se da como nombre del denunciante Emilio, mientras que en los demás artículos se le llama Eulalio. 
ciado ante las autoridades competentes las irregularidades en la publicación de Memorias de Paulina, así como su contenido. En la defensa de Jorge Ainslie, responsable de la publicación, estuvieron presentes los licenciados Gustavo A. Baz, ${ }^{26}$ Talavera y Antenor Lescano. Los acusadores leyeron los capítulos $\mathrm{V}$ y X del folleto. Después de plantear los argumentos respectivos, tanto de la parte acusadora como de la del acusado, el jurado decidió, por unanimidad, que la novela en cuestión "ataca la moral pública”. Además del castigo decretado para Ainslie —un mes en la cárcel—, se recogieron los ejemplares disponibles del texto.

Después del jurado de calificación vino el jurado de sentencia, con los mismos protagonistas. El resultado fue la aplicación de la pena mínima para Ainslie, que sus abogados defensores consideraron un éxito, dado que el acusador (el señor Ortega), había pedido la máxima. Cabe mencionar que en la reseña que "Timoteo" hace del juicio en la Revista Universal - y por tanto sesgada a favor del acusado-, se alaba de manera especial la facilidad oratoria de Manuel G. Prieto, uno de los abogados de Ainslie — ausente en la primera etapa del juicio-, quien logró conmover al auditorio al referir la situación emocional penosa de la madre del acusado:

y en cuanto a Ainslie, se dirigió al corazón de los jurados, pintando con poéticas y conmovedoras frases a la madre de Ainslie, esperando un fallo que iba a infamar a su hijo, que no había cometido ni aconsejado ni defendido vicio o delito alguno. Una salva de aplausos saludó las últimas frases del orador.

El 19 de noviembre del mismo año apareció en El Monitor Republicano la noticia de que algunos colegas del joven Ainslie informaban que estaba enfermo de pulmonía. El 26 de diciembre aparece en $E l$ Foro la noticia de que se abrirá el testamento de Ainslie, para lo cual se llama a sus acreedores o personas relacionadas con él a acudir al juzgado $3^{\circ}$ de lo civil. Si es que estuvo en prisión un mes, entre octubre y noviembre, no es descabellado considerar que haya desarrollado la enfermedad en prisión, por lo que se le puede considerar como una víctima colateral de la censura.

26 Gustavo Baz (1852-1904), fue diputado federal (1876-1888). Periodista, poeta, dramaturgo (Diccionario Enciclopédico de México). 


\section{OTROS ESCÁNDALOS}

Negrete también visitó la delegación, al parecer brevemente, por un altercado con un tal licenciado Carlos Álvarez Rul. La disputa ocurrió en el Teatro Nacional, donde se hicieron de palabras y cruzaron algunos golpes. Álvarez afirmó que Negrete sacó su pistola e intentó dispararla en dos ocasiones, sin consecuencia alguna. Algunas personas lograron separarlos. Negrete fue llevado a la inspección de policía en ese momento, mientras que Álvarez prometió presentarse por su propia voluntad más tarde.

No fue el único alboroto en el que se vio involucrado el periodista. En febrero del mismo año tuvo un enfrentamiento con el "millonario" Manuel Iturbe, ${ }^{27}$ también en el Teatro Nacional. Aparentemente el señor Iturbe estaba molesto por un artículo sin firma que atribuyó a Negrete. Cuando se encontraron en el teatro intercambiaron algunos golpes. Iturbe afirmó ante la policía que Negrete lo había atacado por la espalda. Francisco Bulnes, quien años después se haría famoso con sus libros antirrevolucionarios El verdadero Juárez y El verdadero Díaz, publicó una aclaración en el periódico donde afirmó ser él el autor del artículo que Iturbe consideró como ofensivo. En la misma fecha, Negrete declaró que nunca atacó por la espalda a Iturbe, como lo prueba el hecho de que cayó de espaldas en la barandilla del teatro, lo cual hubiera sido imposible de haber estado a espaldas de su contrincante.

Quedaría por investigar si Negrete se vio envuelto en más enfrentamientos. En todo caso, es claro que le gustaba provocar con sus artículos, y que al menos dos personas se consideraron aludidas en sus escritos y reaccionaron de manera más o menos violenta.

\section{POSDATA}

Las Memorias de Paulina es un libro menor, escrito con afanes sensacionalistas, de épater les bourgeois. A juzgar por lo investigado en este artículo, cumplió con su cometido. Vale la pena citar las palabras de

\footnotetext{
27 Manuel Iturbe debe haber sido primo de Francisco Iturbe, dueño de una de las fortunas mexicanas más importantes del siglo XIX, entre cuyas propiedades se contaba "la casa de los azulejos".
} 
Antenor Lescano, uno de los abogados defensores de Ainslie en el juicio, cuando ya todo había pasado. En una carta a la Revista Universal, desde donde se originó el escándalo, Lescano dice que se ha dicho que él defendió las Memorias de Paulina y que no es así: él defendió a Ainslie, no a la novela:

En mi concepto, y como dije en mi defensa, el folleto en cuestión no contiene nada denunciable; es la recopilación de artículos ya publicados desde hace un año en los periódicos de la capital, en su mayor parte un plagio literario en que colaboran notablemente Alfonso Karr y H. de Villemessant. El capítulo del "Divorcio" denunciado, es una traducción literal de Jeremías Bentham, obra que sirve de texto en nuestra escuela de jurisprudencia por recomendación del gobierno. Por otra el libro no es denunciable en los términos de la ley, porque no aconseja ningún vicio. Yo ignoro si hay en él alusiones personales, porque en tal caso, están para mí completamente veladas. ("Remitido":1).

Agrega su opinión sobre el relato, consciente del ya aludido "efecto paradójico" de la censura:

Creo que sin la importancia que se le dio llamándole "libelo", se habría podrido en el rincón sin venderse ni un ejemplar; y puede acusarse de su venta a las imprudencias de la prensa que le dio, atacándolo, un prestigio de inmoralidad que no tiene. Yo no creo que una generación que se ha destetado con el decálogo del padre Ripalda, con "El camino para llegar al cielo" del padre Claret, con el "Cantar de los cantares" de Salomón, con el "Citador de la Biblia" de Pigault Lebrun, con las novelas de Dumas y con "Gustavo el calavera" de Paul de Kock, que se ha desvelado en las representaciones de la "Bella Elena", de "Sensitiva", de "Barba Azul" y que presenta, en fin, como quinta esencia de su poder intelectual a una niña de nueve años personificando a la "gran duquesa"; esta generación, repito, no tiene el derecho de alarmarse por un volumen insustancial que ha sido condenado por todos los lectores por tanto más que por descomedido.

Y concluye: "hoy condena otro jurado un libro majadero, que yo habría relegado al más solemne desprecio”. 
Bibliografía

Altamirano, Ignacio M. "Renacimiento de la literatura mexicana: la novela”, en Estudios sobre la novela mexicana. Emmanuel Carballo (ed.). México: Universidad Nacional Autónoma de México / Universidad de Colima, 1988. 15-62.

Carballo, Emmanuel. Historia de las letras mexicanas en el siglo XIX. Guadalajara: Universidad de Guadalajara / Xalli, 1991.

Defoe, Daniel. Moll Flanders. Introducción de G.A. Aitken. Londres: Dent., 1969 [Moll Flanders. Londres: Everyman's Library 1837].

Delgado, Rafael. "La novela", en Estudios sobre la novela mexicana. Emmanuel Carballo (ed.). México: Universidad Nacional Autónoma de México / Universidad de Colima, 1988. 131-140.

Diccionario Enciclopédico de México. México: A. León, 1993, 6 t.

Gamboa, Federico. La novela mexicana. José Emilio Pacheco (ed.). México: Universidad Nacional Autónoma de México / Universidad de Colima, 1988.

Karolides, Nicholas J. Margaret Bald y Dawn B. Sova. 120 Banned Books. Nueva York: Checkmark Books, 2005.

LÓpez PORTillo y Rojas, José. "La novela, su concepto y su alcance", en Estudios sobre la novela mexicana. Emmanuel Carballo (ed.). México: Universidad Nacional Autónoma de México / Universidad de Colima, 1988. 89-130.

Muñoz Fernández, Ángel. Fichero bio-bibliográfico de la literatura mexicana del siglo XIX. 2 vols. México: Factoría Ediciones, 1995.

Negrete, José. Memorias de Paulina y Memorias de un merolico. México: Premiá, 1986 (La Matraca, 16. 2a serie).

Piccato, Pablo. "Jurados de imprenta en México: el honor en la construcción de la esfera pública, 1821-1844", en Construcciones impresas. Paula Alonso (comp.). México: Fondo de Cultura Económica, 2004. 139166.

Reyna, María del Carmen. La prensa censurada durante el siglo XIX. México: Secretaría de Educación Pública, 1976 (Sepsetentas, 255).

"Remitido", en Revista Universal. México, IX.2206 (18 de octubre de 1874) 1.

Saborit, Antonio. Los doblados de Tomóchic. Un episodio de historia y literatura. México: Cal y Arena, 1994.

Sandoval, Adriana. "Prólogo" a Obras. V. Crítica literaria de José Juan Tablada. México: Universidad Nacional Autónoma de México, 1994. 728.

-. "Introducción" a El triunfo de Sancho Panza (Mazatlán), continuación 
de Tomóchic. Miserias de México de Heriberto Frías. México: Consejo Nacional para la Cultura y las Artes, 2004. 9-33 (Lecturas Mexicanas. $4^{\mathrm{a}}$ serie).

Warner, Ralph. Historia de la novela mexicana en el siglo XIX. México: Antigua Librería Robredo, 1953. 
